\title{
Simulation of a viscoelastic flexible multibody system using absolute nodal coordinate and fractional derivative methods
}

\author{
Yunqing Zhang • Qiang Tian • Liping Chen • \\ Jingzhou (James) Yang
}

Published online: 6 February 2009

(C) Springer Science+Business Media B.V. 2009

\section{Erratum to: Multibody Syst Dyn \\ DOI 10.1007/s11044-008-9139-x}

1. In Sect. 6.1, line 3 the unit " $\mathbf{k g} / \mathbf{s}^{\mathbf{2}}$ " should be "m/s' $\mathbf{2}$ ", and the Fig. 3 should be

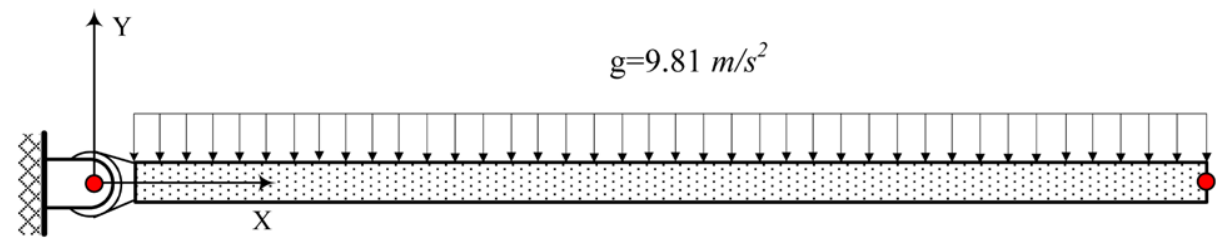

Fig. 3

2. After Fig. 13, line 2, the words "to achieved desired" should be "to achieve desired".

The online version of the original article can be found under doi:10.1007/s11044-008-9139-x.

Y. Zhang · Q. Tian · L. Chen $(\bowtie)$

Center for Computer-Aided Design, School of Mechanical Science \& Engineering,

Huazhong University of Science \& Technology, Wuhan, Hubei 430074, China

e-mail: chenlp@hustcad.com

Y. Zhang

e-mail: zhangyq@hust.edu.cn

Q. Tian

e-mail: tianqiang_hust@yahoo.com.cn

J. Yang

Department of Mechanical Engineering, Texas Tech University, Lubbock, TX 79409, USA

e-mail: james.yang@ttu.edu 